\title{
Metamorfoses do simbólico no brasil RURAL - As TRANSFORMAÇÕES DO INÍCIO DO SÉCULO XXI VISTAS POR MEIO DE UM PERSONAGEM CLÁSSICO DA FORMAÇÃO DO BRASIL, O CAIPIRA
}

\author{
Suzana KLEEB* \\ Arilson FAVARETO**
}

\begin{abstract}
RESUMO: Na análise das transformações brasileiras do século XXI há polarizações envolvendo enaltecimento de mudanças inéditas na história do país e argumentação sobre o alcance limitado destas na crise contemporânea. Este artigo contorna estes extremos afirmando que o período expressa mudanças nas bases da dominação, focalizadas nas metamorfoses do caipira no Brasil rural e interiorano. Esta é retratada em estudos clássicos sobre Cunha-SP e Bofete-SP e revisitada no presente, destacando-se três aspectos: os anos 2000 recompõem o caipira na hierarquia social, combinando alterações e atualizações de velhas estruturas de dominação; novas ruralidades evidenciam processos heterogêneos de preservação de autonomia e tradição do caipira sob formas de contratualização da racionalidade capitalista e do mundo urbano e pós-industrial; aspectos ressaltados pelos clássicos da formação brasileira têm sustentação se entendidos sob o prisma das metamorfoses e articulações do material e do simbólico, das interdependências entre local e extra local, e das interpenetrações entre passado e presente.
\end{abstract}

PALAVRAS-CHAVE: Modos de dominação. Poder simbólico. Nova ruralidade.

\footnotetext{
* Museu de Santo André. Santo André - SP - Brasil. 09010-160 - skleeb@uol.com.br. https://orcid.org/0000-0002-4368-0435.

** UFABC - Universidade Federal do ABC. Centro de Engenharia, Modelagem e Ciências Sociais Aplicadas. Bolsista Produtividade do CNPq. São Bernardo do Campo - SP - Brasil. 09606-045 arilson.favareto@ufabc.edu.br. https://orcid.org/0000-0003-1825-7165.
} 
Introdução

Para autores como Bresser-Pereira (2014) a segunda década do século XXI, mais do que por uma crise conjuntural ou pelo fim dos governos do Partido dos Trabalhadores (PT), é marcada pelo esgotamento de um dos grandes ciclos da formação brasileira. Enquanto o período de 1930 até o meio dos anos 1970 foi, em diferentes etapas, o momento de afirmação do nacional-desenvolvimentismo, os anos compreendidos entre 1988 e 2014 podem ser entendidos como o ciclo organizado em torno das ideias de cidadania e democracia. Recriaram-se instituições democráticas após 20 anos de ditadura, e esta reconstrução se fez cimentada pelo compromisso assumido pelo Estado brasileiro de expandir direitos para uma população beneficiada apenas muito parcialmente pelo processo de modernização característico da urbanização e da industrialização com que se tentou, no ciclo anterior, pôr fim ao passado agrário do país e suas heranças.

A Constituição de 1988 consolidou marcos institucionais deste novo ciclo. Nela se buscou garantir diversos direitos como educação, saúde e assistência social. Mas, com um paradoxo: no mesmo momento em que o Estado brasileiro assumia este conjunto de compromissos, no que se poderia chamar de contrato social em torno da criação de um estado de bem-estar, ainda que com os limites de um país na semiperiferia do capitalismo internacional, o Brasil vivia uma crise de financiamento brutal. Isso ajuda a entender as ambiguidades dos anos 1990, quando os governos conduziram políticas econômicas voltadas à estabilização inflacionária e à modernização da base produtiva, que poderiam ser classificadas como de orientação neoliberal, e, ao mesmo tempo, operavam a organização de sistemas nacionais de implementação das políticas pactuadas na redemocratização, caso típico do Sistema Único de Saúde (SUS) ou da extensão dos direitos previdenciários aos trabalhadores rurais. Estas ambiguidades, em certo sentido, explicam os progressos verificados nos indicadores sociais, sobretudo de educação, mas também o ritmo lento e heterogêneo desta melhoria e também o impasse ou mesmo a piora vista em outros domínios, como a pobreza e o desemprego.

Nos anos 2000 parecia que o paradoxo tinha sido equacionado de melhor forma. O país cresceu continuadamente a taxas razoáveis - em torno de 3,5\% ao ano -, a pobreza declinou significativamente, houve uma condição de virtual pleno emprego, com taxas em torno de 5\%. Tais resultados foram expressão de uma agenda ampla, sustentada por uma coalizão de forças sociais igualmente plural. Nela estavam representados nada menos do que todos os principais segmentos organizados da sociedade brasileira - do capital financeiro ao industrial, do agronegócio aos 
ambientalistas, passando pelas organizações dos trabalhadores. Porém, tão ampla e diversa coalizão não duraria muito. O mesmo Bresser-Pereira $(2014$, p.343) nomina o período como "o pacto que não houve", indicando justamente algo de ilusório na proposta de que todos os segmentos poderiam ganhar simultaneamente por muito tempo. Gradativamente a partir de 2007-2008 as condições começaram a se deteriorar, até atingir seu ápice no meio da década atual, quando houve a deposição da presidente Dilma Rousseff e a reorientação radical da agenda do Estado brasileiro.

No final da segunda década do século XXI, quando este texto é escrito, predomina na agenda nacional um desmonte do aparato de políticas e programas que levaram à melhoria dos indicadores durante o ciclo que agora se encontra em crise e a deterioração de indicadores sociais já é reconhecida nas estatísticas oficiais: crescimento econômico baixíssimo, 13 milhões de desempregados, 7 milhões de pessoas voltando ou ingressando na condição de pobres somente entre 2014 e 2017, volta do crescimento da mortalidade infantil, entre outros aspectos. Para alguns, isso se explica por conta do novo momento da economia internacional, após a crise financeira dos meados dos anos 2000. Para outros, por boicote das elites. Para uma terceira leitura, pelas insuficiências do modelo que vinha sendo adotado. Ou ainda, por uma combinação de todas estas explicações.

Para este texto não importa entrar na discussão dos fatores de declínio desta etapa do ciclo cidadania e desenvolvimento. O intuito é outro: interrogar o alcance das mudanças verificadas, sobretudo na sua etapa mais recente. Também sobre isso restam controvérsias: para uns, os anos 2000 nada mais foram do que uma década de ilusões, agora desfeitas com a crise; para outros, momento de mudanças nunca vistas na história do país, agora boicotadas por uma revanche das elites. O que se propõe é sair deste maniqueísmo e do horizonte de curto prazo. Mais especificamente, propõe-se analisar de que maneira as mudanças deste período se somam a transformações de longo prazo vividas pela sociedade brasileira, herdeiras dos ciclos anteriores de urbanização e industrialização. Trata-se de colocar o período atual sob escrutínio de uma perspectiva mais alongada no tempo, capaz de decantar ou de evidenciar estruturas mais profundas da formação social brasileira, e seu contraste com o que foi feito durante a agenda do Estado brasileiro nesses tempos mais recentes.

A ideia subjacente é que a centralidade dada à agenda social no período dos governos petistas se soma e é em certa medida filtrada por características específicas de certas formações territoriais, com seus modos de dominação assentados há décadas, e com seus personagens arquetípicos representativos destas formas de dominação, moldando assim, dialeticamente, uma metamorfose destas configurações territoriais e das figuras sociais a elas associadas. Somente por meio deste recurso analítico se 
podem compreender os significados mais profundos do ciclo da expansão da cidadania e dos direitos, em especial como eles afetaram domínios específicos da vida social do país ${ }^{4}$. No caso das próximas páginas, se privilegia um destes domínios, aquele que diz respeito às condições de vida e de reprodução social das populações rurais.

Explicitado o olhar que se pretende empreender, cabe dizer algo a respeito do objeto. Por que esta escolha pelo Brasil rural e interiorano? Com efeito, uma das marcas do período dos governos petistas foi o alcance das políticas sociais junto a uma população que, mesmo ao longo de todo o ciclo anterior, havia permanecido de certa forma apartada dos circuitos de acumulação, ou atingida apenas de maneira fronteiriça pelo fenômeno da urbanização e da industrialização. Singer (2011) afirma justamente que é aí, na incorporação do que Caio Prado Jr. (1976) havia chamado de setor inorgânico da economia brasileira à vida política e econômica, que se constituíram as bases sociais de sustentação do lulismo. Lula e seu partido, de berço operário, gradativamente mudaram o eixo de seu apoio na sociedade brasileira, das classes médias intelectualizadas e da classe trabalhadora tradicional para o Brasil interiorano e rural.

É certo que esses dois autores ao mencionarem a categoria setor inorgânico se referem a uma região determinada, que corresponde grosso modo ao Sertão semiárido nordestino. Mas, os processos sociais vistos ali foram, em certa medida, válidos para outras áreas, como as adjacências rurais de regiões urbanas e metropolitanas, mesmo no interior paulista. Ali predominou por muito tempo a figura social do caipira, bastante presente em estudos clássicos da sociologia e da antropologia dedicados ao rural e às transformações sociais. Este era associado historicamente à rusticidade e à precariedade, quando não a adjetivos ainda piores; resultado de sua condição de isolamento e de pouca integração aos ditames da vida moderna. Mais do que a materialidade da condição caipira, há uma simbolização a respeito da sua posição nas maneiras de se conceber o passado, o futuro, e neles, o lugar conferido às populações pobres, que pode ser interrogada à luz das transformações vividas ao largo da história do Brasil, com destaque para o último período.

Este é um ângulo ainda pouco privilegiado, que envolve indagar como essas transformações se expressam nas formas de sociabilidade, seus conflitos e, principalmente, nos padrões de dominação e como estes se condensam nas trajetórias

\footnotetext{
${ }^{4}$ Esta ideia organiza um conjunto de estudos realizados no âmbito do projeto de pesquisa "Mudanças de longo prazo e metamorfoses da dominação nas regiões rurais ou interioranas do Brasil" (2015-2019), sob a coordenação do segundo dos autores deste artigo, e com a participação de vários pesquisadores, entre eles a autora principal. $\mathrm{O}$ projeto, ao qual este artigo se vincula, foi realizado na Universidade Federal do $A B C$ e no Cebrap e contou com apoio do CNPq.
} 
dos personagens e das configurações sociais, enredados em teias de interdependência. Como sugere Bourdieu (1980), a análise dos modos de dominação, privilegiando as formas de ação social e a simbolização da realidade social, permite entender de que maneira heranças estruturais e a liberdade relativa dos indivíduos se combinam, evitando um enfoque excessivamente abrangente e que faça desaparecer no horizonte o protagonismo dos agentes na moldagem das formações sociais nas quais estão inseridos.

A lente de análise utilizada aqui foi apresentada mais detidamente em Favareto et al. (2015) e mescla elementos de sociologia relacional e do institucionalismo histórico. Para este texto, duas proposições ali contidas são centrais. Primeira, a ideia de que existe uma dupla interdependência: entre as trajetórias sociais dos indivíduos representativos de personagens históricos arquetípicos, neste caso o caipira e os habitantes rurais, e a trajetória da configuração territorial em que vivem; e entre a trajetória do território e movimentos mais amplos de transformação da realidade que incidem sobre esta configuração e os modos de dominação que lhe são típicos, neste caso, os ciclos do desenvolvimento brasileiro e sua repercussão sobre as formas de dominação de regiões rurais e interioranas. Segunda proposição: nestas interdependências há uma dialética envolvendo o velho e o novo, o sincrônico e o diacrônico, o exógeno e o endógeno. Isto é, os aspectos exógenos ao território, como a agenda do Estado ou as mudanças culturais e econômicas mais amplas, ao mesmo tempo são filtradas pela configuração territorial, com sua hierarquia interna e com as formas de dominação que sustentam essa hierarquia, mas, também, de forma disruptiva ou incremental, alteram elementos desta ordem social local, mudando as condições em que essa filtragem e refração das tendências externas acontecem. $\mathrm{O}$ resultado desta filtragem, que em Favareto et al. (2015) denominou-se de processo de percolação, tem sua síntese nas metamorfoses que se quer evidenciar. Com esta dupla proposição se evita a autonomização do local, de um lado, e também o outro extremo que consiste em ver os territórios como mero espaço de manifestação de dinâmicas econômicas e de poder que sobre ele incidem. Ao mesmo tempo que se busca conectar passado e presente, o local e o externo, se confere centralidade às estruturas e relações da configuração territorial.

Para compreender como se organiza este processo em uma abordagem empírica propõe-se um exame em dois municípios interioranos paulistas - Cunha e Bofete - nos quais indicadores sociais e econômicos explicitam, entre os anos $2000 \mathrm{e}$ 2010, melhoras significativas. Além disso, ambos os municípios são exemplos para uma análise de trajetória de longo prazo, pois foram motivo de pesquisas entre os anos 1940 e 1950, com Emilio Willems (1947) em Cunha e Antonio Candido (2010) em 
Bofete. Ambos focalizaram momentos de transição que refletiram transformações e ajustes nas formas de vida, nas relações de sociabilidade e no sistema de valores da simbologia do caipira tradicional em choque com os processos de expansão urbanoindustrial presente nas áreas interioranas do estado de São Paulo naquelas décadas. Desta experiência, um paralelo pode ser empreendido em um momento recente em que uma nova transição, dos anos 2000-2015, esteve em curso. Este período de ampliação do acesso a direitos e serviços e, ao mesmo tempo, paulatina perda de fôlego dos processos industriais, revalorização de ambientes rurais associados ao bem-estar e qualidade de vida, forma interessante quadro para evidenciar como se processaram metamorfoses nos modos de ser e de viver da figura remanescente do caipira, enfocando suas estratégias de articulação à sociedade e às dinâmicas territoriais, as formas de adaptação, incorporações e reinterpretações de traços de comportamento.

Para proceder a esta análise uma primeira seção focaliza as características típicas do caipira, presente em autores como Emilio Willems ou, antes dele, Monteiro Lobato, mas analisada de forma sociogenética em Antonio Candido, recuperando assim a formação histórica da cultura caipira em São Paulo (JACKSON, 2002). Nas duas seções seguintes se introduz como o caipira se apresentou nos meados dos anos 1940/50 a partir das obras de Willems (1947) e Candido (2010), iluminando desencaixes e heterogeneidades que os atributos simbólicos do caipira evidenciaram naquele momento de alavancagem do Brasil urbano e industrial, buscando romper com seu passado agrário. E, por fim, mais duas seções abordam como, nos momentos recentes, dos anos 2000, é possível apontar heterogeneidades na organização do universo simbólico nesses dois municípios, com destaque para as formas como as características do caipira se metamorfosearam em cada um deles. Ao final, uma conclusão enfeixa as mudanças e como estas dialogam em um movimento diacrônico, ressaltando transformações em cada configuração territorial ao largo do tempo, e também em um corte sincrônico, com privilégio aos contrastes entre as duas configurações sociais no tempo presente.

O resultado final é a demonstração de que as figuras clássicas da formação do Brasil seguem protagonistas das dinâmicas territoriais e das configurações contemporâneas, obviamente metamorfoseadas, tanto no que diz respeito à base econômica que sustenta seus modos de vida, como nas formas simbólicas de sua representação. Por meio do desvelar destas metamorfoses e da heterogeneidade de sua manifestação espacial, o texto aborda continuidades e rupturas nesses processos, evitando narrativas que tendem a absolutizar certos aspectos unilaterais das mudanças, como os discursos que superestimam ou subestimam o alcance das políticas sociais 
dos anos 2000, ou noutro campo da literatura, os significados da chamada nova ruralidade.

\section{O caipira, sua gênese e a conformação de seu universo simbólico}

Diferente de outras culturas regionais que se manifestam com orgulho, como as do sertanejo ou do gaúcho, Dória e Bastos (2018) lembram que a cultura caipira é tradicionalmente envergonhada, dissimulada, algo que não se explicita, nem se celebra. Lembram o episódio de revolta dos habitantes de Cunha-SP por ocasião da publicação de livro de Willems (1947), no qual retratava habitantes locais valendo-se daquela categoria. Talvez se deva a Monteiro Lobato a fixação desta imagem deletéria do caipira, por meio do seu personagem Jeca-Tatu em Urupês. Mesmo com o atenuante de que não seria sua culpa estar assim, o caipira de Lobato é apresentado como aquele cujo "inconsciente filosofar grulha nessa palavra atravessada de fatalismo e modorra. Nada paga a pena. Nem culturas, nem comodidades. De qualquer jeito se vive" (LOBATO, 2007, p.165). É lento, simplório, atrasado, sinônimo de um passado agrário a ser superado.

Em Antonio Candido (2010) os adjetivos dão lugar a substantivos menos valorativos: a cultura caipira é aquela da sociabilidade marcada pela conduta moral ratificada por práticas de solidariedade assentadas predominantemente na obtenção de condições para a subsistência, algo coerente e consistente com a rusticidade e a carência herdadas de sua condição periférica na formação territorial e social. O caipira é fruto da expansão geográfica dos portugueses na Paulistânia, domínios que se projetavam no sentido dos sertões paulista, mineiro e goiano, subjugo dos indígenas ali presentes.

Para exemplificar essas condições, Candido (2010) valeu-se da categoria dos mínimos em que aborda a forma de obtenção dos meios de vida e os limites de sobrevivência física e social desse indivíduo, algo evidenciado por exemplo em sua dieta, que envolve o provisório, na edificação próxima ao pouso precário e em uma tradição de autossuficiência. As relações sociais se organizavam em agrupamentos vicinais, que exerciam função estabilizadora de estrutura de vizinhança e da posse da terra, elementos característicos da vida caipira. Do equilíbrio instável desses mínimos o autor identificou momentos de crise e de rupturas, com tensões e ajustes entre os fatores de alteração e de persistência que reorganizariam a estrutura social. Antonio Candido (2010) demonstrou ainda como traços da mescla entre indígenas e 
portugueses constituíram os traços de personalidade do caipira, e como tais condições nos meados do século XVIII se traduzia em um comportamento de desconfiança, costumes violentos e segregação.

Desta síntese, Candido (2010) evidenciou que a gênese do caipira se construiu a partir de persistências e mudanças incorporadas nos processos que ele qualificou como marcado por relações pré-capitalistas de acumulação, condicionadas à interação com a natureza. Estas condições, presentes até as últimas décadas do século XIX no interior paulista, sofreram um primeiro choque com a expansão cafeeira e da cana-deaçúcar, que trouxeram consigo a dependência econômica ao mercado internacional e, posteriormente, em um segundo momento, junto ao capitalismo urbano-industrial, condicionando novas formas de trabalho, processando um conflito entre uma reorganização ecológica e transformações na dimensão temporal, abrindo espaço para ajustes e metamorfoses tanto em suas condições materiais como em seu universo simbólico.

As acomodações se fizeram de formas diversas, mais ou menos envolventes, a depender de como se deu a integração às novas formas do capitalismo industrial e à modernidade representada pela urbanização. Iluminou-se o rompimento de tradições ancoradas no sistema de valores mediador tanto das resistências como das transformações sociais, com centralidade na família, em eventos festivos e religiosos ligados ao plantio e colheita e às ações comunais. Diante desse universo simbólico e prático, Candido (2010) focalizou que as mudanças foram lentas com metamorfoses na racionalização dos comportamentos, com a introdução de maior monetarização e previsibilidade econômica.

Exatamente deste ponto é que Willems (1947) e Candido (2010) podem ser postos lado a lado, pois apesar de se valerem de metodologias e aportes teóricos distintos, buscaram compreender de que forma a tradição e a modernidade urbanoindustrial se tocam e se distanciam a todo momento em Cunha-SP e em Bofete-SP, e quais desencaixes podem ser vistos no universo simbólico do caipira e em sua articulação com o tecido social envolvente. Por ser este também o percurso que se pretende empreender na atualidade, mas com um olhar retrospectivo para as obras de Willems (1947) e Candido (2010), é que se apresentam as seções seguintes, apoiadas nas reflexões de ambos os autores. 


\section{Cunha de Emilio Willems, entre a tradição e a transição}

Emilio Willems (1947) estudou Cunha-SP por meio da metodologia de estudos de comunidade, visando entender as transformações socioculturais desde a ligação com Guaratinguetá pela rodovia SP 171 nos anos 1930, promovendo a inserção do mundo urbano-industrial e o escoamento da produção agropecuária, especialmente leite. Cabe salientar que Cunha-SP havia tido importância estratégica no século XVIII, pela localização no Caminho Real, utilizado para o transporte de ouro do estado de Minas Gerais para Paraty-RJ. O pequeno núcleo populacional era local de pouso e singelo entreposto comercial, desestruturado posteriormente com a decadência da exploração aurífera. No momento seguinte, a expansão da economia cafeeira não viu na geografia local condições para produção em larga escala, mantendo o município à margem da pujante riqueza do Vale do Paraíba de meados do século XIX. A falta de mobilidade - estradas ruins, distância da ferrovia - mantiveram o município em certo isolamento de 1860 até os anos 1930 quando foi então inaugurada a SP 171. Willems (1947), em sua obra Cunha, tradição e transição em uma cultura rural do Brasil, concluiu que se manteve ali uma feição rural, e a transição para uma ordem social com características urbanas se dava lentamente, restando diversos traços da tradição caipira.

Nos anos 1940 Willems indicou que apenas 5\% dos habitantes moravam na sede urbana e mesmo dentre esses, muitos ainda desenvolviam atividades agropecuárias, pois oportunidades de trabalho na sede eram muito reduzidas. Evidenciou que a estrutura social era constituída por uma elite denominada de graúdos, composta por fazendeiros, comerciantes e capitalistas em uma mescla de expoentes do espaço rural e urbano, representantes de $9 \%$ mais ricos da população. A base mais pobre da sociedade era composta por $62 \%$ da população, e destes a maioria empregava-se em atividades rurais de meação ou arrendamento. Entre os dois extremos estava a classe média heterogênea, com diversidade e desigualdade econômica, mas predominância de moradores urbanos: profissionais liberais, funcionários públicos, pequenos comerciantes, artesãos e empregados urbanos. Os graúdos detinham a dominação simbólica e econômica, e o paternalismo era uma marca senhorial típica nas relações sociais, aceito pelos trabalhadores rurais com sentimentos de respeito associados ao receio, medo e desconfiança. Estes sentimentos interditavam a manifestação de juízos e emoções (WILLEMS, 1947) e evidenciavam relações de dependência e intimidações reelaboradas constantemente. O caipira ou caboclo, como Willems (1947) o denominava, era premido em seus ganhos e lhe era imposto, por meio de constrangimentos sociais e estratégias de autocontrole, o respeito 
a normas de conduta, regras e mediações dos sentimentos cujo traço fundamental era a resignação. Resignação como resistência, poder-se-ia dizer, mas nesta dialética, indubitavelmente como expressão de um modo de dominação física e simbólica.

Willems (1947) demonstrou que na década de 1940 iniciaram-se metamorfoses nas formas de dominação e no arcabouço simbólico em que estavam assentadas as relações de sociabilidade e as instituições coligadas ao sistema de crenças e valores do caipira, articuladas entre a estabilidade e a instabilidade da sociedade e da cultura local. A estabilidade envolvia a manutenção de um sistema econômico baseado na produção de subsistência e nas trocas pré-capitalistas, o isolamento geográfico que apenas paulatinamente introduzia novos elementos culturais, a regularidade de fluxos populacionais mantida pelo equilíbrio entre crescimento vegetativo e êxodo rural, e a inexistência de um movimento de imigração europeia como ocorria nas áreas centrais do estado de São Paulo. Tudo isso concentrava trunfos sociais articulados à tradição, mantendo os grupos familiares coesos. Aliada à tradição, o importante significado da religião e da magia eram também formas de sustentação da coerência interna da cultura local (WILLEMS, 1947).

Ao mesmo tempo, a instabilidade evidenciava a gradativa introdução da dependência de trocas monetárias e a presença de valores econômicos na lógica comercial, ininteligíveis para a maioria da população do meio rural de então. Esta se associava à transição da estrutura produtiva de subsistência para a pecuária de leite, que além da inserção no mercado regional favoreceu o êxodo do trabalhador rural, realçando o desequilíbrio entre população rural e urbana, a favor dos últimos (WILLEMS, 1947). Além destes aspectos, havia também a ampliação das formas de comunicação e de novos caminhos vicinais que favoreceram fluxos de novas práticas culturais e a chegada de portadores de um ideário divergente que poderia romper com o status quo local. Do balanço entre o estável e o instável, Willems (1947, p.168) indicou que a tradição continuaria viva, mas "houve, a bem dizer, uma aceleração no ritmo de desenvolvimento cujos movimentos mais bruscos e incisivos se afiguram ao observador como sintomas de instabilidade, próprios às fases de transição".

Em síntese, das características da configuração social e suas bases de dominação na pesquisa realizada por Emílio Willems (1947), destaca-se que CunhaSP dos anos 1940 expressava polarização entre os graúdos e outros segmentos sociais, sustentada sob um manto de paternalismo familiar, não mais centrado apenas no meio rural. Os moradores destas áreas, especialmente aqueles que não detinham terras e trocavam sua força de trabalho pela sobrevivência, reproduziam comportamentos de resignação, medo e respeito ao senhor, e experimentavam poucas oportunidades de 
modificar sua condição de dependência econômica e a ampliação de seu campo de possíveis. O autor evidencia que o momento estudado, final dos anos 1940 e início dos 1950, expressa um meio de caminho de transição a favor de novas formas de acumulação do capital, ao lado de formas pré-capitalistas, e a emergência de novos padrões culturais, mas pouco digeridos pelo conjunto da população até aquele momento.

\section{Os caipiras de Cunha na atualidade}

Após mais de 60 anos desde os estudos empreendidos por Emílio Willems (1947), no Censo 2010 Cunha-SP apresentou variação negativa de população em relação ao Censo 2000, em $-5,3 \%$, e ainda congrega um percentual alto de domicílios em áreas rurais, 44\%, o maior de todos os municípios do entorno e muito acima da média brasileira. Os ganhos proporcionados pelas políticas sociais são possíveis de mensurar quando se observa que era alto o percentual de população em condições de pobreza, perfazendo 40\% do total da população em 2000. Mas, em 2010 houve uma expressiva redução, baixando este patamar para 18\%. Além disso, a taxa de matrículas no Ensino Médio entre jovens de 15 a 17 anos, que era de 37,3\% em 2000, saltou para 53,6\% em 2010. A renda per capita, apesar do aumento de 2000 para 2010, praticamente é a metade do valor do estado (BRASIL, 2019a).

Cunha-SP tem pouca diversidade econômica e grande dependência do poder público para emprego e proventos, o que se nota por ser a atividade produtiva com maior valor adicionado no Produto Interno Bruto (PIB), em 2016 os setores de serviços e administração pública, na ordem de 171 milhões de reais, seguida de longe pelas demais atividades: agropecuária na ordem de 27 milhões de reais, e indústria, com 8 milhões de reais (BRASIL, 2019b). Observa-se que a atividade tradicional da pecuária, com importante papel no uso de ocupação do solo, não repercute em ganhos e riqueza para Cunha-SP, não garantindo empregos e nem incrementando significativamente os ganhos no município. A atividade industrial, tão importante na região do Vale do Paraíba paulista, não alcançou ali a mesma expressão, observandose a dependência em relação a municípios vizinhos mais dinâmicos, caso de Guaratinguetá e Lorena, tanto para o acesso a serviços como para a obtenção de empregos para parte da população local.

Dos anos 1970 em diante dois fenômenos trouxeram alguma mudança na lógica econômica de Cunha-SP. O primeiro, um grupo de ceramistas artísticos, utilizadores da prestigiada técnica japonesa noborigama aproveitou a boa argila e a 
posição estratégica entre mercados de São Paulo e Rio de Janeiro e instalou-se em Cunha-SP. Esta atividade transformou-se numa espécie de marca local e fortaleceu a formação de uma identidade turística. $O$ segundo fenômeno se explicitou pela disponibilidade de pequenas propriedades, fruto de heranças e economicamente não rentáveis para a atividade agropecuária comercial, as quais, aliado à beleza cênica da paisagem, com seus mares de morros, situada entre as Serras da Mantiqueira, do Mar e da Bocaina, atraíram para Cunha-SP pessoas do Vale do Paraíba e da região metropolitana de São Paulo, dispostas a comprar terras baratas para lazer de finais de semana ou segunda residência.

Estes dois movimentos levaram o caipira a se ajustar, nos moldes definidos por Candido (2010), dividindo não apenas o espaço rural, fisicamente, mas também trunfos, práticas sociais e culturais e oportunidades com os forasteiros. A adaptação ainda é sentida por moradores mais antigos, que têm temor pela perda de suas raízes e tradições, com ruptura na autonomia nas formas e horários de trabalho e descanso, racionalização dos relacionamentos para além do grupo familiar, ampliando necessidades de maleabilidade e traquejo social (KLEEB, 2019).

Dentre os caipiras obrigados a deixar suas terras expressou-se receio de inadaptação da vida nas cidades, na carência de empregos e no alto custo de vida. Por trás deste sentimento encontra-se ainda a instabilidade na interpretação da sociedade e da cultura local, citada por Willems (1947), e de melhores oportunidades, que dialogam diretamente com a ampliação da escolaridade e qualificação profissional, em muitos casos associados a dificuldades logísticas e geracionais, que apenas nos anos mais recentes, pós anos 2000, pareceram se modificar (KLEEB, 2019).

Deste quadro notam-se dois traços em Cunha-SP: primeiro, apesar de poucas transformações econômicas, estas têm trazido mudanças nas formas de condução da vida cotidiana, especialmente para população de áreas rurais, onde há maior desencaixe junto à população que tem mais de 50 anos e vivenciou rupturas nas relações de sociabilidade, valores e crenças ligados à solidariedade vicinal, às formas de trabalho pré-capitalistas, às atividades de caráter comunal com forte apego religioso. Diante da metamorfose dos últimos quarenta anos associada à migração dos jovens, das facilidades de acesso a recursos nos meios urbanos, da maior conectividade física e virtual, das mudanças nas formas de trabalho com ênfase no contrato de diarista, diminuindo a relação tradicional com o patrão, se processou um afastamento gradual e persistente das antigas regulações sociais.

O segundo traço emerge desta condição: desencaixe frente às novas práticas econômicas e sociais, em que, ao mesmo tempo que se vislumbram mudanças, na conexão com outras realidades e grupos sociais que poderiam fomentar oportunidades 
mais inclusivas aos processos econômicos se observa também um rompimento gradual de antigas formas de sociabilidade, envolvendo alterações e rupturas no sistema de disposições sociais e nas formas de condução da vida cotidiana (KLEEB, 2019).

Nota-se, assim, uma lenta metamorfose nos atributos simbólicos do caipira que, ao se despir paulatinamente da dominação e das relações sociais rígidas estabelecidas com os graúdos, no dizer de Willems (1947), encontra barreiras para efetivar os seus interesses. Sua posição é pautada pelo contraditório, pois diante da irresistível força dos agentes exógenos e da necessidade de abertura a mudanças, o caipira estabelece uma posição reativa e resignada calçada na possível e iminente perda de seu lastro tradicional, mediador, na visão de Candido (2010), das resistências e de transformações no corpo simbólico de seu modo de ser e de agir, de suas relações comunais e associativas, da manutenção de vínculos familiares, entre outras.

O jovem, neste contexto, é ainda mais pressionado pela força das mudanças, expressando maior racionalização e individualização de seus interesses, pois tem no seu âmago a vontade e necessidade premente do êxodo rural, rompendo com vínculos comunitários, identitários e geracionais. Neste grupo social os embates são mais abertos e decisivos, inclusive porque estes, na maioria dos casos, já se valeram das oportunidades abertas com maior escolarização, estabilização econômica de seus parentes e, com isso, a abertura de melhores oportunidades frente ao conjunto da sociedade. Também no caso da condição feminina isso se apresenta (FAVARETO, 2019): são diferentes as possibilidades que se abrem nas velhas e novas atividades econômicas e nas formas de seu aproveitamento para as mulheres envolvidas, por exemplo, na pecuária, no turismo ou na agroecologia, pois em cada uma delas se exigem diferentes atributos de conhecimento e de uso do tempo.

Narrativas de agentes sociais explicitaram que o acesso a um campo de possíveis mais amplo se constituiu em um jogo de forças assimétricas que envolvem não apenas a busca de recursos, mas também necessidades de mudanças internas ao indivíduo diante dos preconceitos evidenciados no seu modo de ser. Um morador que nasceu no meio rural e hoje mora no núcleo urbano, indicou que se "sentia oprimido e queria ultrapassar as montanhas" que o separavam da cidade. Ao chegar à sede urbana, ele percebeu que "tinha no pensamento a lógica do espaço rural" que lhe legou discriminações e "sentimentos de restrição e percepção de incapacidade" (KLEEB, 2019, p173-4).

O que se nota é que os impactos de transformação dos aspectos simbólicos de manutenção da vida foram e são sutis. A lenta reorganização social a partir da perda fundamental do vínculo com a terra ou com a fragmentação desta modificou as formas de sociabilidade com paulatino desaparecimento de formas de solidariedade vicinal, 
mutirões e da relação com a produção agropecuária para seu sustento, ocasionando perdas da autonomia e do ajuste ecológico com a natureza, citada por Candido (2010) como uma das características fundamentais do caipira. Ao mesmo tempo, na atualidade, com as perspectivas de ampliação das relações com um turismo rural e a revalorização das amenidades rurais, típicas do que se convencionou chamar de nova ruralidade (FAVARETO, 2007), é possível que determinados aspectos simbólicos que ainda podem ter resistência no âmago de boa parte da população de Cunha-SP, se tornem a base de novas perspectivas, ainda não mensuráveis pois são muito recentes, mas que certamente podem metamorfosear mais uma vez as formas de produção e reprodução social do caipira, agora algo reinventado, atualizado, interdependente às dinâmicas territoriais em marcha.

Estas transformações não se organizam sem dificuldades e embates endógenos e exógenos ao caipira. As relações de respeito, dominação e temor frente ao outro, muito presentes no universo de Cunha-SP até os anos 1940/50, também se diluíram, especialmente na população mais jovem. Os aspectos diversos à percepção de Willems (1947) foram a ocupação do município com novas formas de exploração do capital, as mudanças demográficas, sobretudo com os novos moradores vindos dos centros urbanos, e a atratividade das amenidades rurais, aspectos evidentes com mais vigor desde os primeiros anos do século XXI. Estas mudanças, certamente trarão, no médio prazo, mais um grão de sal para a análise das metamorfoses do simbólico em CunhaSP.

Bofete de Antonio Candido, rupturas do mundo caipira

O estudo sobre agricultores de Bofete-SP constituiu-se na tese de doutoramento em sociologia de Antonio Candido (2010), denominada Os Parceiros do Rio Bonito, estudo sobre o caipira paulista e a transformação dos seus meios de vida, apresentada em 1954 na Universidade de São Paulo (USP). A obra tem importante significado, pois abriu espaço para a análise do papel de grupos sociais até então marginalizados em estudos de interpretação da formação social brasileira, enfatizando-se as transformações do mundo social do caipira, tendo por base empírica aquele município, situado próximo de Botucatu-SP.

Em sua pesquisa, além de enfatizar as contradições do processo de modernização brasileiro com ênfase na urbanização e industrialização dos meados iniciais do século XX, mostrando como o caipira se ligava a estas mudanças, evidenciou a noção de bairro ou grupo de vizinhança como categoria de pesquisa que 
projetava uma unidade mínima de sociabilidade, permeada pelo sentimento de pertencimento, localidade, convivência, solidariedade e religiosidade (CANDIDO, 2010). Nesses bairros havia certa autonomia em relação aos núcleos urbanos (SANTOS, 2013). Esta unidade de análise seria adotada em toda uma linhagem de trabalhos da antropologia e da sociologia rural, como por exemplo se nota na obra de Maria Isaura Pereira de Queiroz (1973).

Bofete-SP é um município com ocupação dos anos de 1840, como local de pouso de tropas e migrantes mineiros e da região de Itapetininga-SP. Apesar de se situar em área de produção cafeeira, sua condição nesta atividade foi meramente periférica, pois as terras menos férteis e a distância do traçado da linha férrea não trouxeram interesse para uma produção comercial em larga escala, como aconteceu com outros municípios relativamente próximos (BUZATO, 2018). Contudo, foi esta atividade que trouxe afluxo de imigrantes, em grande medida italianos, por meio do colonato, modalidade de acesso à terra que configurou a coexistência entre os sítios dos imigrantes e as grandes fazendas partilhando um mesmo território. Estes imigrantes, juntamente com os caboclos, compuseram a base da estrutura social bofetense. Candido (2010, p.118) enfatizou que havia certo confronto entre "a monocultura e a pequena policultura, o latifúndio e o sítio, o imigrante e o caboclo, o presente e o passado", realçando friç̧ões nas bases de dominação de antigos e novos agentes sociais. A crise do café disponibilizou terras e imigrantes mais capitalizados tiveram acesso a pequenas propriedades, enquanto aqueles sem as mesmas condições alcance se viram como empregados ou diaristas rurais ou expulsos para núcleos urbanos desde os anos 1940 (PIZA, 2007).

O tecido social evidenciava uma sociedade que se transformava, ainda que lentamente, com preponderância numérica de figuras do mundo rural como fazendeiros, sitiantes, parceiros, colonos, entre outros. $\mathrm{O}$ fazendeiro era quem detinha capital econômico e político. As antigas famílias carregavam capital simbólico, importante trunfo que lhes legava prestígio e distinção. Os tipos sociais urbanos eram poucos: o comerciante e o funcionário público, mas com peso decisivo nas bases de dominação especialmente com a ampliação dos trunfos sociais convertidos em capital econômico e político. Evidencia-se um rompimento do isolamento e segregação dos bairros, favorecendo a passagem para outro universo de práticas sociais e culturais. Estas levaram a que o morador rural se sentisse bruscamente desajustado e mal aquinhoado quando se equiparava ao morador da cidade (CANDIDO, 2010).

Para entender as transformações da sociedade diante dos processos de urbanização Candido (2010) ressaltou a figura do parceiro, visto como representante menos estabilizado e integrado à vida social e econômica, mas ainda preso à cultura 
tradicional. Ele enfatizou como este dialoga com o restante da sociedade e ressaltou que Bofete-SP mantinha uma resistência da cultura caipira a partir das formas de ocupação da terra e do regime do trabalho. As práticas econômicas, sociais e culturais, a rotina, as técnicas de plantio, a forma como se organizou a regulação do tempo da agricultura, as festividades de plantio e colheita, bem como a importância das práticas de solidariedade vicinal e trocas de serviço em mutirões, foram se transformando em processos endógenos ao grupo familiar.

O empobrecimento da dieta alimentar com o fim de formas de produção autossuficiente, em ruptura clara das formas tradicionais de vida, introduziu um componente novo no universo simbólico do caipira: a fome psíquica, uma espécie de frustração a partir da falta cotidiana de ingredientes que o levava a senti-la mesmo quando a fome física estava satisfeita. Candido (2010) ressaltou que a inserção na economia capitalista teve um papel arrebatador, iluminando de forma sombria os desencaixes com traços de comportamento associados à inquietação, insegurança e saudosismo, envoltos em uma visão de mundo reativa.

Assim o caipira foi se integrando às condições impostas pela economia capitalista, sujeitando-se à intensificação de seu ritmo de trabalho para complementar sua produção e se inserir no mercado, e, por vezes, com a imposição de condições de instabilidade que o incorporaram à vida urbana. Aqueles que resistiram mantendo-se nas áreas rurais venderam suas propriedades, inserindo-se na condição de parceiros. Houve, nos anos 1950, uma concentração de terras, com 57\% compostas por grandes fazendas, impulsionadas pelo avanço da pecuária. Uma nova mudança: a mão de obra, o camarada, era agora pago por mês, forma de pagamento a que o caipira não estava acostumado.

Em síntese, das características da configuração social de Bofete-SP e suas bases de dominação apresentadas por Candido (2010) entre os anos 1940/50 se observam processos crescentes de urbanização e penetração de relações marcadamente capitalistas, levando o caipira a um reajuste ecológico, com ênfase em sua subordinação a novas formas de divisão do trabalho e novos padrões culturais e práticas para as quais foram precisas reorganizações constantes. Estas condições levaram a novos papéis e posições sociais, em que a autonomia e autossuficiência encontravam-se cada vez mais comprimidas e distantes dos padrões de seu arquétipo tradicional. No entanto, ao mesmo tempo, tais mudanças retiraram-no do isolamento e permitiu acesso a outros bens materiais e simbólicos, que nem sempre seriam garantia da melhoria de suas condições econômicas. 


\section{Os caipiras de Bofete na atualidade}

Passados mais de 60 anos desde os estudos de Candido (2010), observa-se que Bofete-SP nos anos 2010 congrega um percentual de 37,5\% de domicílios em áreas rurais, bem menor do que no momento daqueles estudos, mas uma porcentagem ainda significativa quando comparada às médias do estado de São Paulo e do Brasil. A população de Bofete-SP tem crescido lentamente, sendo que entre os últimos Censos ocorreu um aumento de 9,6\%. Houve também avanços em diversos indicadores, fruto das políticas sociais implementadas desde os anos 2000: a população em condições de pobreza, que era de 19\% da população do município em 2000, no ano de 2010 caiu para 10\%. Além disso, a taxa de matrículas no Ensino Médio entre jovens de 15 a 17 anos que era de $40 \%$ em 2000 saltou para 54\% em 2010. A renda per capita, no entanto, que já era modesta em 2000, atingindo $\mathrm{R} \$ 578,00$ continuou baixa em 2010, nos patamares de $\mathrm{R} \$ 601,00$, indicando pouco dinamismo econômico local (BRASIL, 2019a). A atividade produtiva com maior valor adicionado no PIB em 2016 era a de serviços na ordem de 60 milhões reais, seguida pela atividade agropecuária na ordem de 23 milhões reais, e indústria, na ordem de 22 milhões de reais (BRASIL, 2019b). Estes dados indicam a importância do setor terciário e a relevância do setor público.

A mineração de areia e o plantio de eucaliptos se destacam, seguidos pela produção de laranja e cana-de-açúcar, e de pecuária bovina e avicultura. Contudo, a atividade industrial extrativa e pouco diversificada e a inovação tecnológica irregular na área de agropecuária indicam que, em relação aos demais municípios do entorno, Bofete-SP está inserido no bolsão de municípios mais pobres de sua região (BUZATO, 2018). Por outro lado, o fato de se vincular a uma região dinâmica, com importantes municípios como Botucatu-SP e Tatuí-SP, garante a seus moradores acesso a serviços e boa infraestrutura de rodovias vicinais, com ligações com as rodovias Castelo Branco e Marechal Rondon, eixos de mobilidade com outras regiões paulistas e a estados brasileiros.

Esta posição e as condições de conectividade física e virtual têm gerado também uma procura por terras por populações urbanas de outros locais, em fenômeno similar, embora bem menos intenso àquele mencionado para o caso de Cunha-SP. Segundo Buzato (2018) estima-se que tenham sido comercializadas até os dias atuais cerca de 25 mil chácaras para lazer. A ocupação efetiva ainda é baixa, mas tem induzido certa dinamização econômica e, especialmente, ampliada a presença de migrantes entre a população, modificando seus modos de vida (BUZATO, 2018). Estas mudanças, já alertava Candido (2010), mudaram as relações entre o meio urbano 
e rural, metamorfoseando o arcabouço simbólico do caipira e sua percepção de oportunidades de futuro.

A partir de pesquisas de campo realizadas recentemente alguns aspectos puderam ser observados. O primeiro deles é a maior penetração de relações tipicamente capitalistas nas áreas rurais, com ampliação da habilidade em lidar com a monetarização da vida, com a racionalidade econômica e com a previsibilidade na balança entre gastos e ganhos na produção e comercialização. Ao lado desta característica, valores, crenças e tradições típicas do modo de ser do caipira acabaram distribuindo recursos disponíveis de forma mais igualitária, diluindo bases de dominação que pressionavam as relações entre as elites rurais e os caipiras nos anos 1940, quando o município era prioritariamente rural. O resultado foi maior autonomia na liberdade de escolhas que, coligadas às políticas sociais pós Constituição de 1988, levaram à ampliação da escolarização e do acesso a direitos como previdência social aos idosos, e expansão de possibilidade de captar recursos financeiros para a produção agropecuária por meio de programas como o Programa Nacional de Fortalecimento da Agricultora Familiar (PRONAF). Tais condições expandiram o volume de capitais econômicos e culturais em relação às gerações passadas.

Contudo, é notória a desarticulação das relações comunitárias e da organização da vida social, além da transformação radical da produção autossuficiente de alimentos da dieta destes grupos, pois "quase tudo se compra na cidade", como indicou uma agricultora. Cultivos são localizados na paisagem e sinalizados como abandonados, pois "não vale mais pena", conjecturou outro agricultor. Aliás, é muito presente a ideia de que "ninguém mais faz porque está muito sem valor", remetendo à consciência do pouco valor econômico da atividade agropecuária tradicional que sempre lhes identificou e a inviabilidade em empreender o cultivo dos alimentos que garantiam a sobrevivência e a troca com outros vizinhos, estímulo para a garantia nutricional da mesa caipira. Hoje em dia a alimentação é satisfeita no supermercado da cidade ou em municípios vizinhos, a preços mais altos e qualidade, na maioria das vezes, inferior. Com o pouco valor para o trabalho rural, é corriqueiro ouvir que as gerações dos filhos dos agricultores familiares geralmente não estão mais na roça e não têm interesse em trocar a vida urbana pela rural. Há, segundo se apurou, até certo desprezo pela vida no campo e, no limite, é apenas local de moradia e não de inversão de trabalho e riquezas.

Dentre as atividades produtivas que são desenvolvidas em Bofete-SP, aquela que melhor expressa a atuação do caipira e sua metamorfose envolve os contratos de integração na produção de frangos. Esta modalidade vem substituir, desde os anos 1980, a atividade de parceria. Os agricultores integrados são os novos parceiros. Trata- 
se de situação limite entre o ajustamento da autonomia do caipira - em que se preserva algum controle da forma de produzir e de gerir o tempo na unidade familiar, dividindo-o com outras atividades produtivas como lazer - e sua subordinação à racionalidade da produção capitalista à qual está agora integrado por um contrato formal. A autonomia é relativa, incompleta, pois não há mais exatamente o domínio sobre a produção, uma vez que quem determina a quantidade e como se produz são empresas integradoras e o agricultor integrado por meio do contrato de produção deve respeitar os ditames ali especificados. A agroindústria fornece matrizes, insumos e controla a qualidade. Não é mais a palavra empenhada que vale. $\mathrm{Na}$ atualidade a dominação é racionalizada na figura do contrato que preserva a figura do produtor autônomo, mas, submete essa autonomia a uma racionalidade contratualizada, agora formalmente.

A racionalização também pode ser evidenciada em outros âmbitos do cotidiano, como o rompimento dos laços comunitários que sustentavam a lógica de ocupação do bairro e que ficaram resumidos a laços familiares: não há mais interconhecimento entre moradores, apenas relações entre as unidades tocadas por parentes. As relações de solidariedade no trabalho também praticamente desapareceram, individualizando atividades de produção em torno de pessoas frequentemente com mais de 50 anos de idade. Os espaços que garantiam o assentimento às práticas religiosas e culturais, importantes filtros e anteparos para a manutenção de tradições e práticas culturais caipiras, por vezes persistem na paisagem - a igreja permanece bem cuidada marcando um ponto simbolicamente relevante no bairro rural -, mas têm pouca função na agregação dos indivíduos: as festas são agora muito ocasionais e não ocupam mais posição estruturante nas formas de sociabilidade local.

O saudosismo, outra forma de que o caipira se valia para reforçar a tradição, parece estar cada vez mais distante. Especialmente porque o mecanismo do saudosismo é acionado na psique somente quando o presente é muito precário. Nas narrativas de moradores de Bofete-SP, os investimentos das políticas sociais entre os anos 2000 e 2015 trouxeram significativa mudança nas formas de bem-estar que, apesar de crises recentes ainda mantém ganhos na vida dessas populações. Isto se vê na comodidade e melhoria de habitações, comparadas às de outrora, no acesso a veículos e à telefonia, facilitando a conectividade física, ampliando oportunidades de contato familiar e de deslocamento para acessar comercio e serviços. 


\section{Considerações finais}

Ao longo destas páginas procurou-se realçar a importância de situar a análise das transformações ocorridas nos anos 2000 nos marcos de um processo mais longo de metamorfoses nas bases da dominação que afetam as regiões rurais brasileiras, tendo por objeto as recomposições na condição social de um personagem típico da formação do Brasil, o caipira. Três vetores entrelaçados foram evidenciados: i) a penetração constante e crescente de relações capitalistas, mais acentuadamente desde a emergência do Brasil urbano-industrial, afetando acomodações entre tradição e modernidade em áreas rurais paulistas, e retratadas nas obras clássicas de Antonio Candido (2010) e Emilio Willems (1947) - o rural em transição, sob domínio da emergente urbanização e da industrialização; ii) nas últimas três décadas, um conjunto de outros processos sociais que têm como uma de suas principais marcas a emergência de uma nova ruralidade, com a valorização de novos atributos - as chamadas amenidades rurais (ar limpo, paisagens rústicas, modos de vida portadores da tradição cultural e de relações de proximidade), aspectos que enaltecem, em vez de negar, atributos historicamente associados ao agrário e ao caipira permitindo seu reposicionamento - o rural em um mundo altamente urbanizado e mesmo pósindustrial; iii) na última década e meia, a atribuição de um lugar destacado à questão social, e nela aos pobres rurais, em particular - algo que tem como marco a Constituição de 1988 e, mais acentuadamente, a primeira década e meia deste século, com os governos apoiados na chamada agenda social desenvolvimentista.

Deve ter ficado claro como a figura do caipira segue exercendo papel nas configurações sociais rurais e interioranas paulistas, mas com diferenças. Ao contrário do sugerido pelos que vaticinaram seu fim, décadas atrás no rastro da promessa da urbanização e da industrialização vistas no ciclo nacional desenvolvimentista, há, no período recente, uma manutenção de traços do arcabouço simbólico retratado nos estudos dos anos 1940/50. E não por acaso nos dois locais moradores locais se autodenominam, ainda, como caipiras. Mas, não se trata mais do mesmo caipira. Ele se metamorfoseia. Há aberturas e reorganizações com a chegada de novos agentes sociais, mudanças nas formas de trabalho, transformações nas lógicas de dominação, com relações sociais e econômicas que se processam agora de forma mais racionalizada e individualizada, trazendo uma valorização do que antes era motivo de avaliação pejorativa - o rústico, o tradicional, o natural. Estas mudanças nas lógicas da cultura e no arcabouço simbólico são mais sutis do que as mudanças nos indicadores de pobreza ou de emprego, e ocorrem no longo prazo. Só são perceptíveis em perspectiva diacrônica. E, talvez justamente por isso mesmo sejam mais duradouras. 
Sob o ângulo da heterogeneidade sincrônica, ela se expressa na diversidade das inserções de cada um dos municípios analisados - Bofete-SP mais integrado e envolto em uma rede de municípios de médio porte, com ampla mobilidade e integração diversificada: agricultura, pecuária e indústria; Cunha-SP mais assentada na atividade de pecuária extensiva de leite, turismo ascendente, mudanças demográficas com novos moradores atraídos pelas amenidades rurais. Ambas com um setor terciário assumindo a dianteira, tanto na ocupação de trabalho como na geração de divisas, retrato de um momento em que a economia brasileira passa por um processo de desindustrialização e no qual a dependência da exportação de commodities tem efeitos limitados na dinamização das economias e na geração de empregos. Com exceção do que é movido pelo turismo, em Cunha-SP, trata-se predominantemente de um setor de serviços dependente do Estado e de transferências públicas.

Vistos desta maneira, o caso das transformações do caipira nos dois locais, como parte de um processo mais amplo de metamorfoses nas formas de dominação no Brasil contemporâneo, permite ao menos mais três inferências importantes, para além do caso em si. Primeiro, os anos 2000 não parecem, então, ter sido palco de uma redenção dos mais pobres, mas sim de uma não menos importante recomposição de sua situação na hierarquia social. Combinaram-se mudanças - algumas reversíveis, diga-se, como é o caso dos níveis de renda, hoje já afetados com a crise econômica da segunda década do século -, com a atualização de velhas estruturas de dominação nos territórios: dominância urbana e assimetria perante os graúdos, subordinação dos produtores familiares ao capital, não solução das restrições fundiárias, precariedade da inserção econômica na vida social pela via do trabalho, fragilidade das oportunidades econômicas mesmo com maior escolaridade. Segundo, o que a literatura dos estudos rurais chamou de nova ruralidade, com certa empolgação vinte anos atrás, ecoando o que Bernard Kayser (1990) chamara de renascimento rural em um de seus livros, é na verdade um processo muito mais complexo e diferenciado nas distintas configurações territoriais. Menos do que um renascimento, e talvez mais do que uma nova ruralidade, há uma heterogeneização das formas de dominação que ainda precisa ser mais bem compreendida. Nela coexistem velhas formas de exploração da natureza e do trabalho, com novas modalidades de uso dos recursos naturais e de inserção das pessoas. Nela se preserva algo da autonomia e da tradição dos grupos de agricultores como o caipira, mas submetidas a novas formas de contratualização típicas da racionalidade capitalista e de um mundo urbano e pós-industrial. Terceiro, como corolário, se observa que, ao contrário de uma ideia que seduz parte do mundo intelectual brasileiro, muitos aspectos ressaltados nos clássicos da formação do Brasil ainda permanecem úteis à análise, desde que entendidos sob o prisma das metamorfoses e das articulações entre 
o material e o simbólico, das interdependências entre o local e o extra local, e das interpenetrações entre o tempo passado e a experiência presente.

\title{
METAMORPHOSES OF SYMBOLIC IN RURAL BRAZIL - THE TRANSFORMATIONS OF THE EARLY 21ST CENTURY SEEN THROUGH A CLASSIC CHARACTER OF BRAZIL CONFIGURATION, THE “CAIPIRA" (COUNTRY MAN)
}

\begin{abstract}
In the analysis of Brazilian transformations of this 21 st century there are polarizations involving the praise of unprecedented changes in the history of the country and the argument about their limited scope in the contemporary crisis. This article circumvents these extremes by stating that the period expresses changes in the bases of domination, here focused on the metamorphoses of the "caipira" in rural and inland Brazil. This is portrayed in classic studies on Cunha and Bofete (SP) and revisited at present, highlighting three aspects: the 2000s recompose the "caipira' in the social hierarchy, combining changes and updates of old structures of domination; new ruralities show heterogeneous processes of preservation of the "caipira's" autonomy and tradition under the forms of contractualization of capitalist rationality and of the urban and post-industrial world; aspects emphasized by the classics of Brazilian configuration are supported if understood from the perspective of metamorphoses and material and symbolic articulations, interdependencies between local and extra local, and interpenetrations between past and present.
\end{abstract}

KEYWORDS: Modes of Domination. Symbolic Power. New Rurality.

METAMORFOSIS SIMBÓLICAS EN ZONAS RURALES DE BRASIL TRANSFORMACIONES DESDE EL INICIO DEL SIGLO XXI VISTO A TRAVÉS DE UN CARÁCTER CLÁSICO DE LA FORMACIÓN DE BRASIL, EL “CAIPIRA”

RESUMEN: En el análisis de las transformaciones brasileñas de este siglo XXI hay polarizaciones que implican elogios de cambios sin precedentes en la historia del país y el argumento sobre su alcance limitado en la crisis contemporánea. Este artículo evita estos extremos al afirmar que el período expresa cambios en las bases de la 
dominación, centrados en las metamorfosis del "caipira" en las zonas rurales y del interior de Brasil. Esto se retrata en estudios clásicos sobre Cunha y Bofete (SP), así como en las revisiones actuales, destacando tres aspectos: los años 2000 recomponen el "caipira" en la jerarquía social, combinando cambios y actualizaciones de viejas estructuras de dominación; las nuevas ruralidades muestran procesos heterogéneos de preservación de la autonomía y tradición del "caipira" bajo formas de contractualización de la racionalidad capitalista y del mundo urbano y postindustrial; los aspectos enfatizados por los clásicos de la formación brasileña se sostienen si se comprenden desde la perspectiva de las metamorfosis y las articulaciones de lo material y lo simbólico, las interdependencias entre lo local y lo extra local, y las interpenetraciones entre el pasado y el presente.

PALABRAS CLAVE: Modos de dominación. Poder simbólico. Nueva ruralidad.

\section{Referências}

BOURDIEU, Pierre. Le Sens pratique. Paris, Minuit, 1980.

BRASIL. Instituto Brasileiro de Geografia e Estatística. Censos 2000 e 2010.

Disponível em: https://www.ibge.gov.br. Acessado em: 24 nov. 2019a.

BRASIL. Instituto Brasileiro de Geografia e Estatística. IBGE Cidades.

Disponível em: https://cidades.ibge.gov.br. Acessado em: 24 nov. $2019 \mathrm{~b}$.

BRESSER-PEREIRA, Luis C. A construção política do Brasil. São Paulo: Ed. 34 Letras, 2014.

BUZATO, Heidi. A dimensão territorial das formas de reprodução social da agricultura familiar nas Cuestas de Botucatu e no Extremo Sul da Bahia. 2018, 221f. Tese (Doutorado em Planejamento e Gestão do Território) - Universidade Federal do ABC, São Bernardo do Campo, 2018.

CANDIDO, Antonio. Os parceiros do Rio Bonito. Estudo sobre o caipira paulista e a transformação de seus meios de vida. 11ªed. Rio de Janeiro: Ouro sobre azul, 2010.

DÓRIA, Carlos A. e BASTOS, Marcelo C. A culinária caipira da Paulistânia. São Paulo: Três Estrelas, 2018. 
FAVARETO, Ariane. Dinâmicas rurais contemporâneas e configurações sociais de gênero. 2019, 229f. Tese (Doutorado em Ciências Sociais). Instituto de Ciências Humanas, Universidade Federal Rural do Rio de Janeiro. Rio de Janeiro, 2019.

FAVARETO, Arilson. Paradigmas do desenvolvimento rural em questão. São Paulo: Iglu/FAPESP, 2007.

FAVARETO, Arilson et. al. Territórios importam - bases conceituais para uma abordagem relacional do desenvolvimento das regiões rurais ou interioranas no Brasil. ReGis, Brasília, v. 1, n.1, p. 13-33, dez. 2015.

KAYSER, Bernard. La renaissance rurale. Sociologie des campagnes du monde occidental. Paris: Armand Colin, 1990.

JACKSON. Luis C. A tradição esquecida. Os parceiros do Rio Bonito e a sociologia de Antonio Candido. Belo Horizonte: Ed. UFMG/São Paulo: FAPESP, 2002.

KLEEB, Suzana. Metamorfoses da sociabilidade brasileira. Estudos nas configurações territoriais da Bocaina (Vale do Paraíba, São Paulo) e do Lago de Sobradinho (Sertão do São Francisco, Bahia). 2019, 385f. Tese (Doutorado em Planejamento e Gestão do Território). Universidade Federal do ABC, São Bernardo do Campo, 2019.

LOBATO, M. Urupês. Rio de Janeiro: Globo, 2007.

PIZA, João F. A formação de povoados da região de Botucatu. Orientador: Antonio C. Moreira, 2007, 140f. Mestrado (Dissertação em Arquitetura e Urbanismo). Faculdade de Arquitetura e Urbanismo, Universidade de São Paulo, São Paulo, 2007.

PRADO JR. Formação do Brasil Contemporâneo. Colônia. São Paulo: Brasiliense, 1976.

QUEIRÓZ, Maria Isaura Pereira de. Bairros Rurais Paulistas. Dinâmica das relações bairro rural-cidade. São Paulo: Livraria Duas Cidades, 1973.

SANTOS, Ana C. dos. Pelo movimento: natureza e modernidade em "Os Parceiros do Rio Bonito" de Antonio Candido. 2013. 223f. Tese (Doutorado em Sociologia) - Instituto de Filosofia e Ciências Humanas, Universidade Estadual de Campinas, Campinas, 2013.

SINGER, André. Os sentidos do lulismo. São Paulo: Cia. das Letras, 2011. 
Metamorfoses do simbólico no Brasil rural - As transformações do início do século XXI vistas por meio de um personagem clássico da formação do Brasil, o caipira

WILLEMS, Emilio. Cunha. Tradição e transição em uma cultura rural do Brasil. Secretaria da Agricultura - Diretoria de Publicidade Agrícola - Governo do Estado de São Paulo. São Paulo, 1947.

Recebido em 06/08/2019.

Aprovado em 31/10/2019. 